\title{
Toxicity measurements in aqueous solution during ozonation of mono-chlorophenols
}

\author{
Neng-Chou Shang ${ }^{\mathrm{a}, *}$, Yue-Hwa Yu ${ }^{\mathrm{a}}$, Hwong-Wen Ma ${ }^{\mathrm{a}}$, Cheng-Hsin Chang ${ }^{\mathrm{b}}$, Ming-Long Liou ${ }^{\mathrm{a}}$ \\ ${ }^{\mathrm{a}}$ Graduate Institute of Environmental Engineering, National Taiwan University, 71 Chou-Shan Rd., Taipei, Taiwan, ROC \\ ${ }^{\mathrm{b}}$ Department of Civil Engineering, Tamkang University, 151 Ying-Chuan Rd., Tamsui, Taipei County, Taiwan, ROC
}

Received 28 February 2004; accepted 23 March 2005

Available online 24 August 2005

\begin{abstract}
The Microtox toxicity and Oxygen Uptake Rate (OUR) inhibition tests were conducted to monitor the variation of toxicity during ozonation of 2-chlorophenol (2-CP), 3-chlorophenol (3-CP) and 4-chlorophenol (4-CP) under neutral conditions. The results revealed that the oxidized 2-CP solution exhibited new toxicity to pure bacteria and mixed microorganisms in the early stage of ozonation. The largest inhibition of OUR appeared at one mol of applied ozone dosage per mol of initial 2-CP, and the percentage of inhibition was 63.8\%. In addition, ozonated 3-CP and 4-CP also significantly induced new aqueous toxicity, if these toxic intermediates were not further ozonated. Comparing the variation of toxicity and the hydroxylated/chlorinated intermediates formed, 3-chloro-catechol, 2-chloro-2, 4-hexadienedioic acid and the dimmer compounds may be related to the sources of toxicity during the ozonation of 2-CP.
\end{abstract}

(C) 2005 Elsevier Ltd. All rights reserved.

Keywords: Ozonation; Mono-chlorophenols; Toxicity; Microtox; Oxygen uptake rate (OUR)

\section{Introduction}

Many aromatic compounds, including the chloro-, nitrosubstituted aromatic compounds or substituted phenols have been reported to be quite bioresistant in nature and in treatment plants. One group of these compounds, the chlorophenols (CPs) is typically biorefractory or toxic in the aqueous environment due to their chloro substituent (Stefan et al., 1995). Related studies have examined the feasibility of using partial oxidation of chlorophenols by ozone or other oxidants (advanced oxidation processes, AOPs) to promote biodegradability for subsequent biological treatment and to reduce the toxicity of effluent (Trapido et al., 1997; Hu and Yu, 1994; Stockinger et al., 1995; Yu and $\mathrm{Hu}, 1994)$. In general, the byproducts formed in these oxidation processes are mainly low-molecular-weight (organic acids) or hydroxylated compounds, which are presumed to be more biodegradable or less toxic than their parent compounds (Miller et al., 1988; Lipczynska-Kochany

\footnotetext{
* Corresponding author. Fax: +886223628043.

E-mail address: shangnc@ntu.edu.tw (N.-C. Shang).
}

0301-4797/\$ - see front matter (C) 2005 Elsevier Ltd. All rights reserved. doi:10.1016/j.jenvman.2005.03.015 and Bolton, 1992). Therefore, Adams et al. (Adams et al., 1997) indicated that the ozonation of 4-CP and 2, 4-dichlorophenol (DCP) significantly enhanced their biodegradability by the unacclimated microbial seed obtained from a domestic wastewater treatment plant's activated sludge, and that the ultimate COD (chemical oxygen demand) removal increased about $50 \%$ for these two chlorophenols. Trapido et al. also reported that ozonation of CPs (2-CP, 4-CP, 4-chlororesorcinol, 6-chloro-m-cresol and 2, 4-dichlorophenols) decreases their toxicity according to the Daphnia magna $24 \mathrm{~h}$ toxicity test when ozone treatment leads to $90-95 \%$ removal of CPs.

On the other hand, the toxic intermediates of oxidative treatment prior to the detoxification of the chlorinated aromatic compounds have been reported (Hirvonen et al., 2000; Svenson and Hynning, 1997; Manilal et al., 1992). Hirvonen et al. reported that the hydroxylation of chlorophenols and formation of dimeric intermediates were involved in the oxidation of chlorophenols by ozone and $\mathrm{UV} / \mathrm{H}_{2} \mathrm{O}_{2}$ processes. Hydroxylated chlorophenols, chlorodihydroxybiphenyls and dichlorodihydroxybiphenyls were formed in both oxidation treatments of monochlorophenols (2-CP and 4-CP). These byproducts showed the characteristics of high molecular weight or the presence of 
chlorinated intermediates, which are of concern due to their toxicity. Svenson and Hynning indicated that photolytic degradation of 2, 4, 6-trichlorophenol was found to increase aqueous toxicity measured by the Microtox bioassay system, and this increasing toxicity was mainly generated from the 3, 5-dichlorocatechol formed. In light of the above developments, oxidation treatment of mono-chlorophenols by ozone is studied in this investigation, and attention is focused on the variation of toxicity. In this study, acute toxicity of pure CPs and ozonated solutions is assessed by the Microtox toxicity assay (Nirmalakhandan et al., 1994), and the inhibition of the activated sludge system is measured by Oxygen Uptake Rate (OUR).

\section{Materials and methods}

\subsection{Process of ozonation}

Fig. 1 shows a schematic diagram of the ozonation apparatus employed as a semi-batch type. Ozonation was performed in a lab-scale bubble column reactor with a magnetic stirrer. All the components in this system are made from acrypoly glass, Teflon or stainless steel. The ozone generator was manufactured by JEU TU CO., Japan (Series No, SG-01A-PSA4). The ozone gas was introduced into a diffuser in the bottom of the reactor. The concentration of ozone gas was measured by the potassium iodide technique based on the standard methods (APHA, 1992). The monochlorophenols used in this study were 2-chlorophenol, 3-chlorophenol and 4-chlorophenol. They were obtained from Merck (reagent grade). The volume of the reaction solution was $1000 \mathrm{~mL}$ and Milli-Q water was used in all experiments. The $\mathrm{pH}$ was fixed at $\mathrm{pH} 7$ in all ozonation processes. A pH controller (SUNTEX, pH/ORP Controller PC-310), an adding pump (Cole-Parmer 7553-80) and $0.2 \mathrm{~N}$ $\mathrm{NaOH}$ or $\mathrm{H}_{2} \mathrm{SO}_{4}$ solution was utilized to control $\mathrm{pH}$ during ozonation. Table 1 lists other detailed operating conditions of ozonation.

The CPs concentration during ozonation was analyzed by HPLC (Bio-Rad 1350) equipped with a UV/VIS spectrophotometer (Bio-Rad 1706) employing a wavelength of $280 \mathrm{~nm}$ and a C18 reverse-phase column (Phenomenex). The mobile phase consisted of acetonitrile, water and acetic acid, regulated at a 580: 420: 5.7 by volume ratio. The concentration of chloride ion was measured by using a Dionex 2000i ion chromatograph (IC) with a Dionex AS4A anion separator column. A TOC analyzer (O-I-Analytical, model 700) was employed to measure the total organic carbon (TOC) of the ozonated solution. Chemical oxygen demand (COD) was analyzed according to the standard methods (APHA. 2350E, 1992).

\subsection{Microtox assay}

Acute toxicity of the pure compounds and solutions of their ozonated intermediates was measured by the Microtox toxicity technique, using Photobacterium phosphoreum. Analysis was conducted according to the standard Microtox test procedures using a Microtox analyzer (Model 500, Microbics Corp, Carlsbad, CA). In this paper, the $\mathrm{EC}_{50,15}$ min value (that is the effective concentration of the sample that causes $50 \%$ inactivation of the test bacteria in $15 \mathrm{~min}$ ) was used to trace the change in toxicity during ozonation. The Microtox test was operated in duplicate with a resulting average CV (coefficient of variation) of $15 \%$. The $\mathrm{pH}$ value of all test samples was maintained at 7 to prevent the $\mathrm{pH}-$ effect, before toxicity was measured. The microorganism

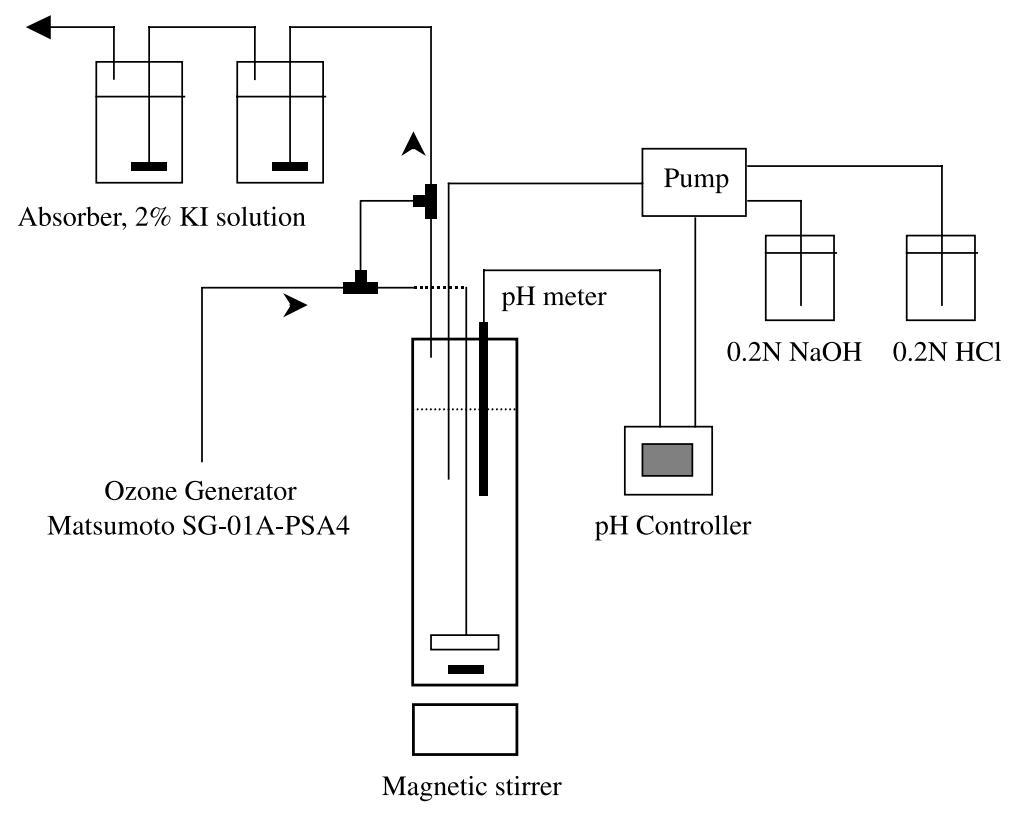

Fig. 1. Assemblage of ozonation system. 
Table 1

Operating conditions of ozonation

\begin{tabular}{ll}
\hline Gas phase & \\
Flow rate, $q$ & $976 \mathrm{~mL} / \mathrm{min}$ \\
Pressure & $1 \mathrm{~kg} / \mathrm{cm}^{2}$ \\
Influent ozone concentration, $\left[\mathrm{O}_{3}\right]_{\text {in }}$ & $77.0 \mathrm{mg} / \mathrm{L}$ \\
Ozone dosage applied, $q \times\left[\mathrm{O}_{3}\right]_{\text {in }}$ & $75.2 \mathrm{mg} / \mathrm{min}(1.57 \mathrm{mmol} / \mathrm{min})$ \\
Liquid phase & \\
Bubble column reactor & $327 \mathrm{~mm}$ high, $70 \mathrm{~mm}$ diameter \\
Volume of solution & $1000 \mathrm{~mL}$ \\
Initial CPs concentration & $100 \mathrm{mg} / \mathrm{L}(0.78 \mathrm{mM})$ \\
$200 \mathrm{mg} / \mathrm{L}(1.56 \mathrm{mM})$ & \\
$\mathrm{PH}$ & $7.0 \pm 0.1$ \\
\hline
\end{tabular}

used in the Microtox produces light with peak intensity at $490 \mathrm{~nm}$. Consequently, highly colored aqueous samples may cause nonspecific reductions in light level when analyzed according to the standard Microtox assay procedure. Any light level reduction could not be distinguished from one caused by toxicants. Therefore, a color correction procedure was incorporated in this study. For the Microtox test it is required to complete the measurement within $48 \mathrm{~h}$ after sampling, and the samples must be stored in a $4{ }^{\circ} \mathrm{C}$ environment. The $\mathrm{EC}_{50}$-values expressed as percentage $(\%)$ were used in this study. In addition, $\mathrm{EC}_{50}$ values were transformed to toxicity units (TU) according to the approach introduced by Brown (1968). A toxicity unit is defined as follows: $\mathrm{TU}_{\mathrm{i}}=\mathrm{C}_{\mathrm{i}} / \mathrm{EC}_{50, \mathrm{i}}$, where $\mathrm{C}_{\mathrm{i}}$ is the concentration of component $i$. Based on this, the TU values of the samples were determined by dividing TOC $(\mathrm{mg} / \mathrm{L})$ by the Microtox $\mathrm{EC}_{50}$ value (\%) as follows Eq. (1):

$\mathrm{TU}=\mathrm{TOC}(\mathrm{mg} / \mathrm{L}) / \mathrm{EC}_{50}(\%)$

\subsection{Oxygen Uptake Rate inhibition test}

The microbial seed used for the Oxygen Uptake Rate (OUR) inhibition test was the activated sludge taken from a domestic wastewater treatment plant. The working sludge was not run through an acclimation process, and this sludge could be used within $6 \mathrm{~h}$ after sludge samples were collected from the treatment plant.

A dissolved oxygen (DO) meter with an electronic stirrer (YSI 5000) was used for OUR determinations. The mixed liquid suspended solid (MLSS) concentration was $217 \mathrm{mg} / \mathrm{L}$ during the whole OUR test, and the working volume was the standard BOD bottle of $300 \mathrm{~mL}$. The organic carbon sources from glucose (non-inhibitory material) or test samples were fed at $50 \mathrm{mg} / \mathrm{L}$ of COD concentration, and the nutrient substrates were applied as $1 \mathrm{~mL}$ of solution $\mathrm{A}$ and $\mathrm{B}$, described later. In this study, the OUR of glucose was the control value for defining the percentage of inhibition, which was determined as follows Eq. (2):

$$
\begin{aligned}
\text { Inhibition } \%= & {\left[\left(\mathrm{OUR}_{\text {samples }}-\mathrm{OUR}_{\text {glucose }}\right) / \mathrm{OUR}_{\text {glucose }}\right] } \\
& \times 100=\left[1-\left(\mathrm{OUR}_{\text {samples }} / \mathrm{OUR}_{\text {glucose }}\right)\right] \times 100
\end{aligned}
$$

The nutrient substrates used during the OUR test were as follows (Talinli and Tokta, 1994): solution A contained the following quantities per liter: $\mathrm{K}_{2} \mathrm{HPO}_{4}, 320 \mathrm{~g}$ : $\mathrm{KH}_{2} \mathrm{PO}_{4}$, $160 \mathrm{~g} ; \mathrm{NH}_{4} \mathrm{Cl}, 120 \mathrm{~g}$. Solution $\mathrm{B}$ contained the following quantities per liter: $\mathrm{MgSO}_{4} \cdot 7 \mathrm{H}_{2} \mathrm{O}, 15 \mathrm{~g} ; \mathrm{FeSO}_{4} \cdot 7 \mathrm{H}_{2} \mathrm{O}$, $0.5 \mathrm{~g} ; \mathrm{ZnSO}_{4} \cdot 7 \mathrm{H}_{2} \mathrm{O}, 0.5 \mathrm{~g} ; \mathrm{MnSO}_{4} \cdot 3 \mathrm{H}_{2} \mathrm{O}, 0.5 \mathrm{~g} ; \mathrm{CaCl}_{2}$, $2 \mathrm{~g}$.

The OUR test was measured over a period of $15 \mathrm{~min}$. During the measurement of OUR, the sludge was kept suspended with an electronic stirrer attached to a DO meter. The average OUR in each vessel was determined by plotting time versus DO concentrations. In this study, the specific OUR (SOUR) value was calculated as follows (Eq. (3)):

SOUR $=$ OUR/MLSS $=\left(\mathrm{mg} \mathrm{O}_{2} / \mathrm{h}\right) / \mathrm{g}$ MLSS

\section{Results and discussion}

\subsection{Decomposition and mineralization rates of chlorophenols by ozonation}

Previous studies have indicated that the decomposition and mineralization rates of chlorophenols (CPs) by ozone treatment followed pseudo-first order kinetics: $-\mathrm{d} C / \mathrm{d} t=$ $k C$, where $C$ is the concentration of TOC $(\mathrm{mg} / \mathrm{L})$ or chlorophenols $(\mathrm{mg} / \mathrm{L})$, and $k$ is the pseudo-first order rate constant (time ${ }^{-1}$ ) (Kuo, 1999; Shen et al., 1995). In this study, the pseudo-first order rate constant was determined by plotting reaction time versus the $\ln \left(C / C_{0}\right)$ values of CPs or TOC concentrations. Figs. 2 and 3 illustrate the curves of decomposition and mineralization of CPs by ozone treatment at $\mathrm{pH} 7$ and ozone dosage of $75.2 \mathrm{mg} / \mathrm{min}$. The curves were found to be well fitted to the pseudo-first order kinetics, and the $R$ square values were more than 0.93 .

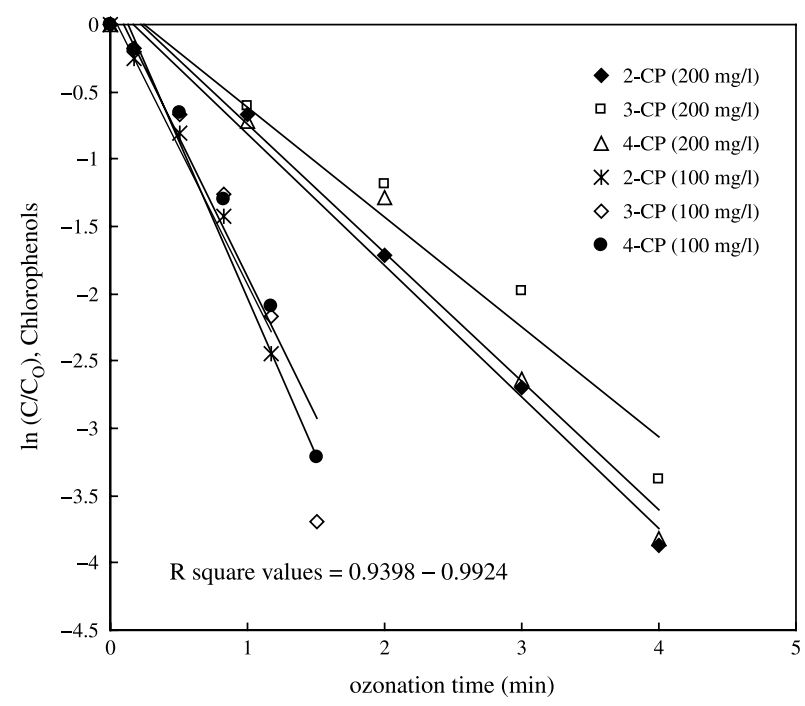

Fig. 2. The decomposition of chlorophenols (initial conc. 100 and $200 \mathrm{mg} / \mathrm{L}$ ) by ozone treatment under $\mathrm{pH} 7$ solution, ozone dosage applied $=75.2 \mathrm{mg} / \mathrm{min}$. 


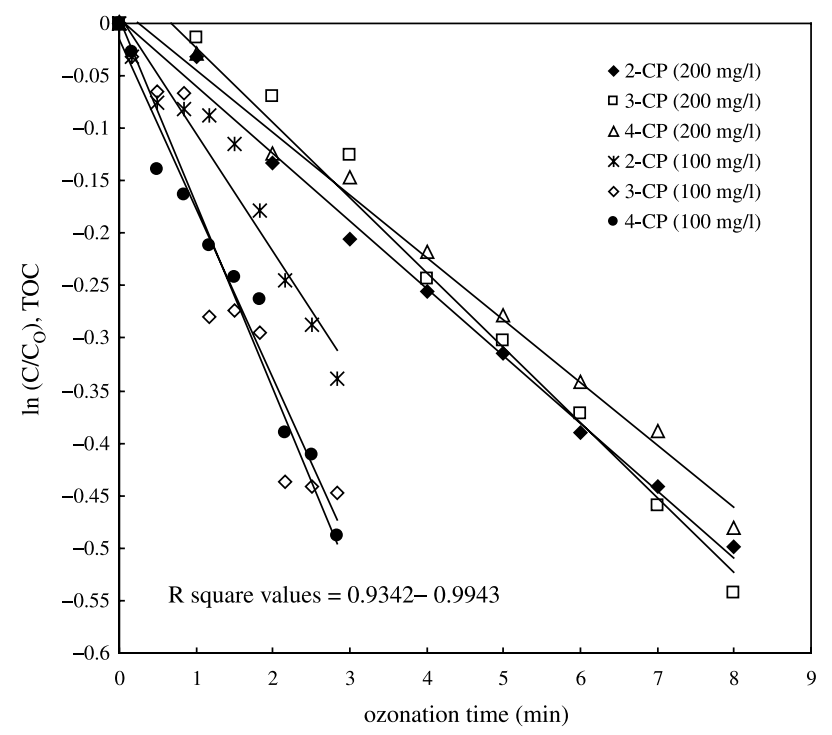

Fig. 3. The decomposition of TOC during ozonation of chlorophenols (initial conc. 100 and $200 \mathrm{mg} / \mathrm{L}$ ) under $\mathrm{pH} 7$ solution, ozone dosage applied $=75.2 \mathrm{mg} / \mathrm{min}$.

Therefore, the slopes of the linear curves are the pseudo-first order rate constants and are summarized in Table 2, in which $k_{\mathrm{CPs}}$ and $k_{\mathrm{TOC}}$ are the pseudo-first order rate constants of decomposition of CPs and mineralization by ozonation, respectively. Comparison of the $k_{\mathrm{CPs}}$ and $k_{\mathrm{TOC}}$ values showed only slightly different results in the ozonation of 2-CP, 3-CP and 4-CP. Therefore, the o, $\mathrm{m}$, and p-substitutes do not significantly affect the decomposition and mineralization rates of CPs by ozonation under neutral conditions.

\subsection{Variation of toxicity during ozonation of chlorophenols}

\subsubsection{Microtox toxicity and OUR inhibition test}

The Microtox toxicity and Oxygen Uptake Rate (OUR) inhibition tests were conducted to monitor the variation of toxicity. The Microtox assay used the P. phosphoreum to determine the influence of toxic substances on pure bacteria. The OUR inhibition test utilized mixed bacteria from unacclimated activated sludge to evaluate the phenomenon of inhibition by ozonation byproducts.

Fig. 4 compares the variation of specific OUR values and Microtox $\mathrm{EC}_{50}(\%)$ during ozonation of 2-CP at an initial concentration of $200 \mathrm{mg} / \mathrm{L}$ and $\mathrm{pH}$ 7. The results revealed that the Specific OUR value of unozonated 2-CP was higher

Table 2

Decomposition and mineralization rates of chlorophenols by ozonation in pH 7 solution and ozone dosage applied $75.2 \mathrm{mg} / \mathrm{min}$ condition

\begin{tabular}{|c|c|c|c|c|c|c|}
\hline \multirow{2}{*}{$\begin{array}{l}\text { Concentration } \\
(\mathrm{mg} / \mathrm{L})\end{array}$} & \multicolumn{2}{|l|}{$2-\mathrm{CP}$} & \multicolumn{2}{|l|}{$3-\mathrm{CP}$} & \multicolumn{2}{|l|}{ 4-CP } \\
\hline & 100 & 200 & 100 & 200 & 100 & 200 \\
\hline $\mathrm{k}_{\mathrm{CPs}}{ }^{\mathrm{a}}$ & 2.04 & 0.977 & 2.338 & 0.815 & 2.085 & 0.955 \\
\hline $\mathrm{k}_{\mathrm{TOC}}{ }^{\mathrm{b}}$ & 0.112 & 0.064 & 0.177 & 0.072 & 0.162 & 0.060 \\
\hline
\end{tabular}

a Pseudo-first order rate constant on the basis of CPs removal, $\min ^{-1}$.

b Pseudo-first order rate constant on the basis of TOC removal, $\min ^{-2}$.

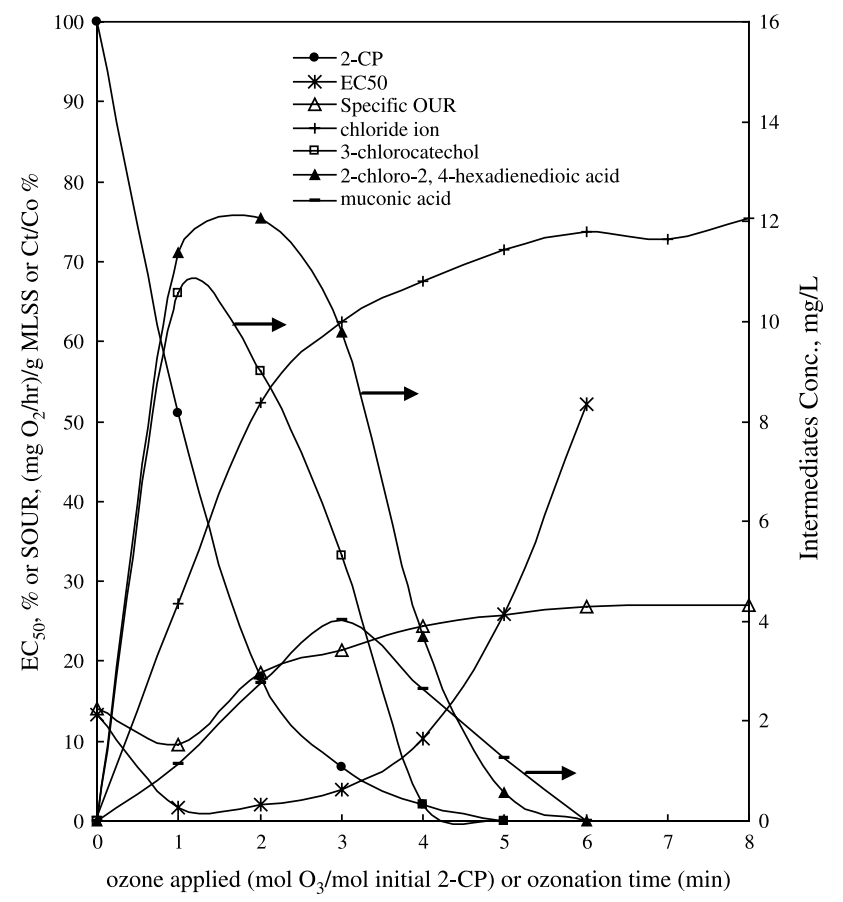

Fig. 4. The variation of 2-CP, intermediates and chloride during ozonation of 2-chlorophenol (initial conc. $200 \mathrm{mg} / \mathrm{L}$ ) in $\mathrm{pH} 7$ condition.

than that of the ozonated solution after $1 \mathrm{~min}$ of reaction time (when the ozone applied was $1 \mathrm{~mol} \mathrm{O}_{3}$ per mol of initial 2-CP). Since the lower SOUR value implies more inhibition to bacteria, ozonation of 2-CP significantly induced new aqueous toxicity to mixed microorganisms. Further ozonation could gradually increase the SOUR value after 2 min of reaction. The curve of the $\mathrm{EC}_{50}(\%)$ value showed a similar trend, the unozonated 2-CP solution having a higher value than the ozonated solution within 4 min of reaction time. The ozonated 2-CP also significantly induced new aqueous toxicity to pure bacteria in the Microtox toxicity. Some results of the Microtox test of ozonated 2-CP have been described in our previous study (Shang et al., 2002; 2003). Summarizing these results, the ozonated solution significantly induced new aqueous toxicity to the microorganisms. The oxidized 2-CP intermediates produced more serious toxicity to pure bacteria or mixed microorganisms than the parent compounds during the early stage of ozonation. The amount of ozone consumed that led to the maximum toxicity or inhibition was one mol per mol of initial 2-CP.

Based on the results of the OUR test, the percentage of OUR inhibition was calculated by Eq. (2) and is shown in Fig. 5. The percentage of inhibition is negative if the OUR value of the test sample is less than the control value (in this study the OUR of glucose was the control value). Contrarily, the inhibition is positive when the OUR samples $_{\text {is more than }}$

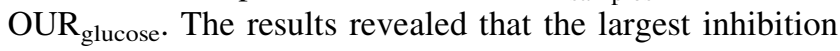
of OUR appeared at $1 \mathrm{~min}$ of ozonation time, and the percentage of inhibition was $-63.8 \%$. Further ozonation after $1 \mathrm{~min}$ of reaction could gradually decrease the degree 


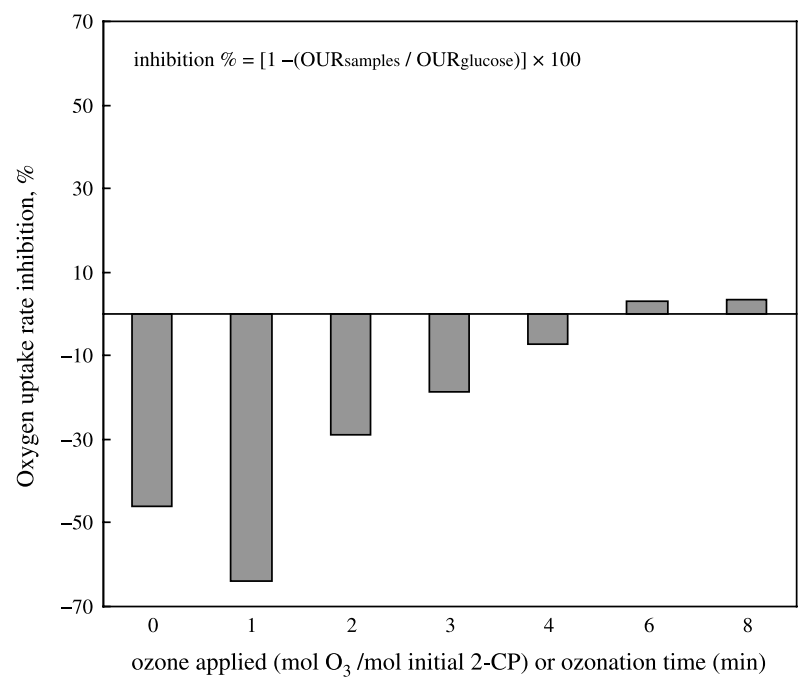

Fig. 5. Results of the OUR inhibition during ozonation of 2-CP (initial conc. $200 \mathrm{mg} / \mathrm{L}$ ) in $\mathrm{pH} 7$ condition.

of inhibition. However, the percentage of inhibition was negative until $6 \mathrm{~min}$ of oxidation, meaning the ozonated solutions became more biodegradable than glucose after 6 min of reaction.

Fig. 6 summarizes the results of the Microtox TU values during ozonation of 2-CP, 3-CP and 4-CP at $\mathrm{pH}$ 7. The TU value increased with time until a maximum value was reached. After the maximum point, the TU value decreased gradually with further oxidation and eventually became nontoxic. This result revealed that ozonation of 2-CP, 3-CP and 4-CP significantly induced new aqueous toxicity, and the increasing toxicity normally reached a peak in the early stage of ozonation. Some discussion of the Microtox test for ozonated chlorophenols is presented in our previously study (Shang et al., 2002; 2003). In summary, the intermediates of oxidized chlorophenols might produce the risk of acute

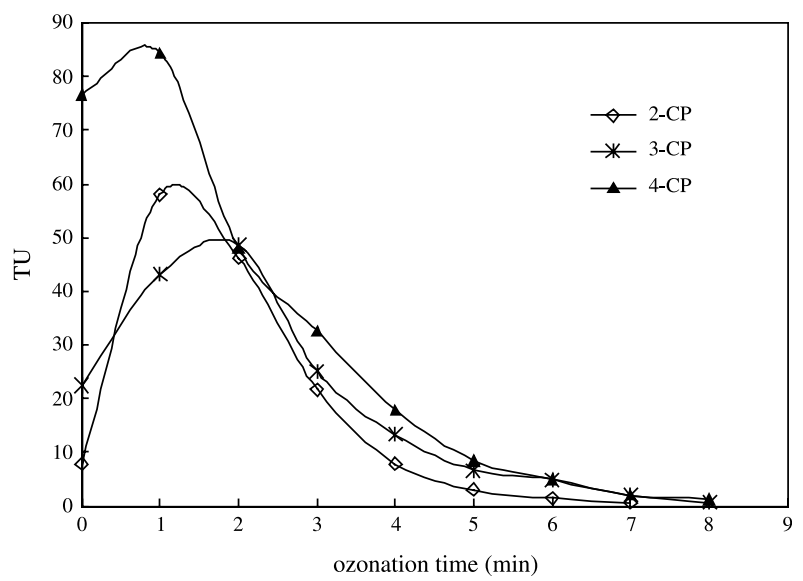

Fig. 6. The comparison of toxicity unit (TU) during ozonation of 2-CP, 3$\mathrm{CP}$ and 4-CP under $\mathrm{pH} 7$ solution, TU $=$ TOC $(\mathrm{mg} / \mathrm{L}) / \mathrm{EC}_{50}(\%)$. toxicity to pure or mixed microorganisms, if these toxic intermediates are not further oxidized.

\subsection{Relation between toxicity and ozonated intermediates}

Fig. 4 illustrates the concentration of reaction products with ozonation time for the 2-CP solution. According to the HPLC analysis, 3-chloro-catechol and 2-chloro-2, 4-hexadienedioic acid were the major byproducts within $3 \mathrm{~min}$ of ozonation. The hydroxylated intermediate of 3-chloro-catechol was formed by electrophilic aromatic substitution of the hydroxyl group at the ortho-position. 2-chloro-2, 4-hexadienedioic acid was the next-step oxidant of 3-chloro-catechol through cleavage of the aromatic ring. Another study also indicated similar mechanisms in ozonation of 2-CP (Kuo and Huang, 1995). In addition, 3-chloro-catechol might be the precursor compound of the dimmer structure formed through the mechanism of oxidative coupling. The dimmer compounds are shown in Fig. 7. (Shang et al., 2002; Hirvonen et al., 2000). Hirvonen et al. (2000) indicated that the hydroxylated or chlorinated dimeric intermediates (chlorodihydroxylbiphenols and dichlorodihydroxylbiphenols) were formed during ozonation of 2-CP and 4-CP in acidic solution, and these dimmer compounds suggested that the two benzene rings were combined through $\mathrm{C}-\mathrm{C}$ bonding. In our previous study, a compound of molecular weight 252 was detected by mass spectrometry in ozonation of 2-CP, which suggests that the dimmer compounds could be formed. Comparing the variation of toxicity and hydroxylated/chlorinated intermediates formed, we found that the maximum toxicity or inhibition to microorganisms occurred during the reaction period when these compounds formed in ozonated 2-CP. Base on this finding, 3-chloro-catechol, 2-chloro-2, 4-hexadienedioic acid and the dimmer compound may be well related to the sources of toxicity during the early stage of ozonation of 2-CP.

According to the HPLC analysis in this study, ozonated 3-CP and 4-CP formed chloro-catechols and chloromuconic acids as the major intermediates after preliminary ozonation (Fig. 7) (Kuo and Huang, 1995). The intermediates of 4-chloro-catechol and 3-chloro-2, 4-hexadienedioic acid were the major byproducts during the ozonation of 4-CP. 4-chloro-catechol was formed by electrophilic aromatic substitution of the hydroxyl group at the orthoposition during the ozonation of 4-CP. 3-chloro-2, 4-hexadienedioic acid was the next-step oxidant of 3-chloro-catechol. However, two kinds of chloro-catechols transformed into chloro-muconic acids were observed in the ozonation of 3-CP. The hydroxylated byproducts of chlorocatechols were formed by electrophilic aromatic substitution in the ortho-position for both sides of the hydroxyl group on the benzene ring. Therefore, two kinds of chloromuconic acids could be detected. In addition, our previous paper has reported the formation of high molecular weight compounds in ozonated 2-CP, 3-CP and 4-CP based on mass 


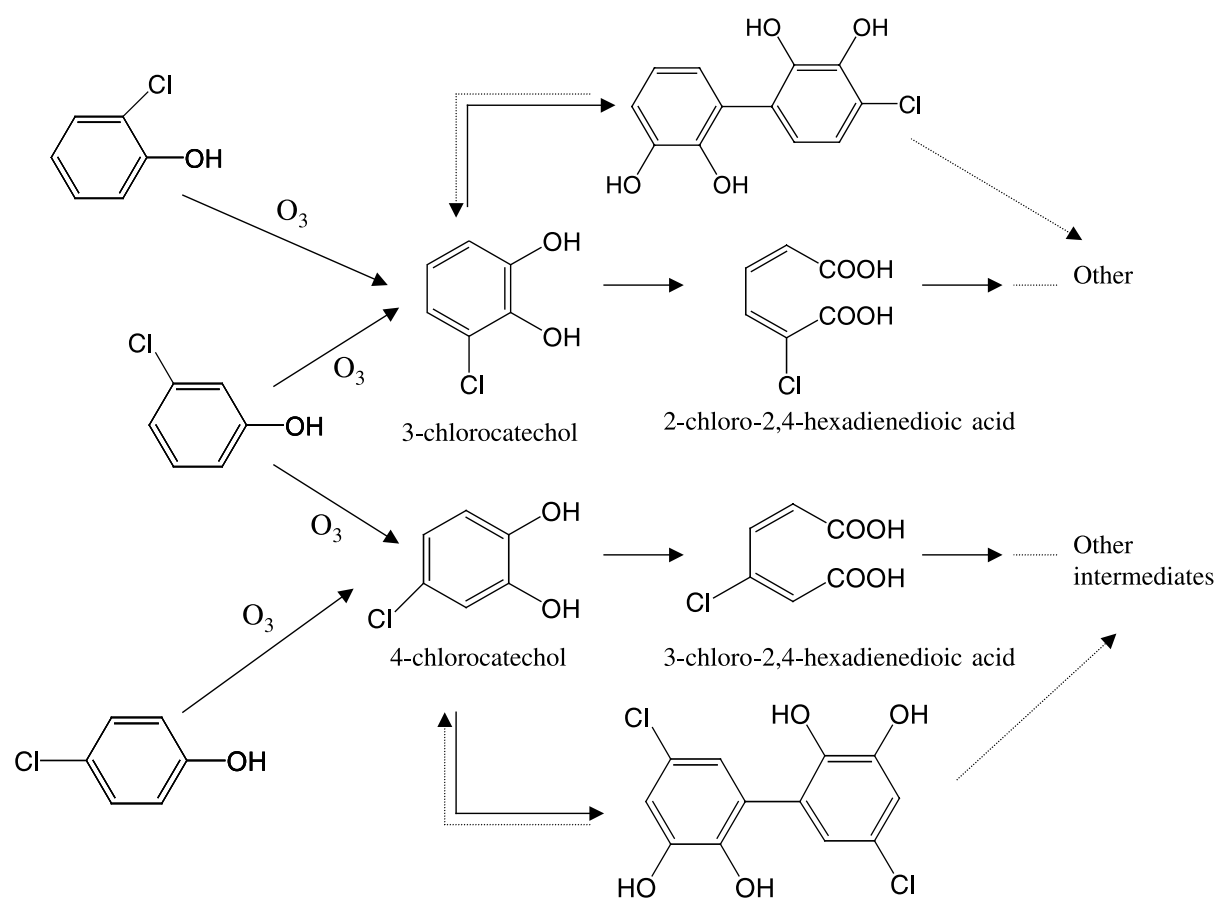

Fig. 7. Formation of hydroxylated/chlorinated dimeric compounds, chloro-catechols and chloro-muconic acids during ozonation of 2-CP, 3-CP and 4-CP.

spectrometry. (Shang et al., 2002). These high molecular weight compounds contain a hydroxylated/chlorinated substituent on the benzene ring, and the structures corresponding to the detected molecular weight are suggested in Fig. 7. Nevertheless, this study still could not indicate very clearly which of the above intermediates caused the increasing toxicity and inhibition of microorganisms.

\section{Conclusions}

The results of this study revealed that the decomposition of 2-CP, 3-CP and 4-CP and the mineralization rates of TOC followed pseudo-first order kinetics during ozonation. The oxidized 2-CP solution induced new toxicity during the early stage of ozonation, as shown from Microtox $\mathrm{EC}_{50}$ and OUR inhibition tests. The results of the Microtox and OUR inhibition tests exhibited very similar trends in this study; the highest toxicity and the largest percentage of inhibition both occurred at $1 \mathrm{~mol}$ of applied ozone dosage per mol of initial 2-CP. Comparing the variation of toxicity and the hydroxylated/chlorinated intermediates formed, 3-chlorocatechol, 2-chloro-2, 4-hexadienedioic acid and the dimmer compound may be related to the sources of toxicity to pure bacteria and mixed microorganisms during the early stage of ozonation of 2-CP. In addition, the results revealed that ozonation of 2-CP, 3-CP and 4-CP significantly induced new aqueous toxicity if these toxic intermediates were not further ozonated.

\section{Acknowledgements}

The authors would like to thank the National Science Council of the Republic of China, Taiwan for financially supporting this research under Contract No. NSC 90-2211E-002-039.

\section{References}

Adams, C.D., Cozzens, R.A., Kim, B.J., 1997. Effects of ozonation on the biodegradability of substituted phenols. Water Res. 31 (10), 26552663.

APHA, 1992.Anon., 1992. Ozone demand/requirement-semi batch method, 18th ed., Standard Methods for Examination of Water and Wastewater APHA, Washington, DC pp. 2-42.

Brown, V.M., 1968. The calculation of the acute toxicity of mixtures of poisons to rainbow trout. Water Res. 2, 723-733.

Hirvonen, A., Trapido, M., Hentunen, J., Tarhanen, J., 2000. Formation of hydroxylated and dimeric intermediates during oxidaton of chlorinated phenols in aqueous solution. Chemosphere 41, 1211-1218.

Hu, S.T., Yu, Y.H., 1994. Preozonation of chlorophenolic wastewater for subsequent biological treatment. Ozone Sci. Eng. 16, 13-28.

Kuo, W.S., 1999. Synergistic effects of combination of photolysis and ozonation on destruction of chlorophenols in water. Chemosphere 39 (11), 1853-1860.

Kuo, C.H., Huang, C.H., 1995. Aqueous phase ozonation of chlorophenols. J. Hazard. Mater. 41, 31-45.

Lipczynska-Kochany, E., Bolton, J.R., 1992. Flash photolysis/HPLC applications. Environ. Sci. Technol. 26, 259-261.

Manilal, V.B., Haridas, A., Alexander, R., Surender, G.D., 1992. Photocatalytic treatment of toxic organics in wastewater: toxicity of photodegradation products. Water Res. 26 (8), 1035-1038. 
Miller, R.M., Singer, G.M., Rosen, J.D., Bartha, R., 1988. Sequential degradation of chlorophenols by photolytic and microbial treatment. Environ. Sci. Technol. 22, 1215-1219.

Nirmalakhandan, N., Arulgnanendran, V., Mohsin, M., Sun, B., Cadena, F., 1994. Toxicity of mixtures of organic chemicals to microorganisms. Water Res. 28 (3), 543-551.

Shang, N.C., Yu, Y.H., Ma, H.W., 2002. Variation of toxicity during the ozonation of monochlorophenolic solutions. J. Environ. Sci. Health A37 (2), 261-271.

Shang, N.C., Yu, Y.H., Ma, H.W., 2003. Variation of toxicity during the ozonation of aromatic compounds in aqueous solution. Adv. Asia Environ. Eng. 3 (1), 43-49.

Shen, Y.S., Ku, Y., Lee, K.C., 1995. The effect of light absorbance on the decomposition of chlorophenols by ultraviolet radiation and $\mathrm{UV} / \mathrm{H}_{2} \mathrm{O}_{2}$ processes. Processes Water Res. 29 (3), 907-914.
Stefan, S., Joachim, A., Rainer, B., 1995. Quantitative structure-toxicity relationships for 80 chlorinated compounds using quantum chemical descriptors. Chemosphere 30 (12), 2397-2414.

Stockinger, H., Heinzle, E., Kut, A.M., 1995. Removal of chloro and nitro aromatic wastewater pollutants by ozonation and biotreatment. Environ. Sci. Technol. 29 (8), 2016-2022.

Svenson, A., Hynning, P.A., 1997. Increased aquatic toxicity following photolytic conversion of an organochloring pollutant. Chemosphere 34 (8), 1685-1692.

Talinli, I., Tokta, S., 1994. Oxygen uptake rate inhibition test: a modified method for priority pollutants. Environ. Technol. 15, 979-988.

Trapido, M., Veressinina, J., Hentunen, K., Hirvonen, A., 1997. Ozonation of chlorophenols: kinetics, byproducts and toxicity. Environ. Technol. $18,325-332$.

Yu, Y.H., Hu, S.T., 1994. Preoxidation of chlorophenolic wastewater for their subsequent biological treatment. Water Sci. Technol. 29 (9), 313-320. 